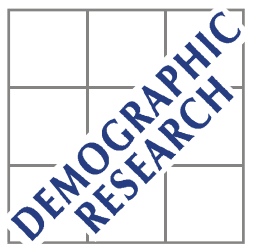

Demographic Research a free, expedited, online journal of peer-reviewed research and commentary in the population sciences published by the Max Planck Institute for Demographic Research Konrad-Zuse Str. 1, D-18057 Rostock · GERMANY www.demographic-research.org

DEMOGRAPHIC RESEARCH

VOLUME 8, ARTICLE 10, PAGES 279-304

PUBLISHED 22 MAY 2003

www.demographic-research.org/Volumes/Vol8/10/

DOI: 10.4054/DemRes.2003.8.10

Research Article

\title{
Is Nursing Home Demand Affected by the Decline in Age Difference Between Spouses?
}

\section{Darius N. Lakdawalla}

Robert F. Schoeni

(C) 2003 Max-Planck-Gesellschaft. 


\section{Table of Contents}

1 Introduction 280

2 Long-term care in the United States 280

3 Conceptual relationship between age gap and 282 nursing home use

4 Methods 284

4.1 Age difference and the risk of widowhood 284

4.2 Marriage and the risk of nursing home entry 286

$\begin{array}{lll}\text { 4.2.1 Data } & 287\end{array}$

4.2.2 Statistical model 293

4.3 Age difference and the nursing home population 294

5 Results 295

5.1 Age difference and the risk of widowhood 295

5.2 Marriage and the risk of nursing home entry 296

5.3 Age difference and the nursing home population 299

6 Discussion 301

7 Acknowledgements 302

References 303 
Research Article

\title{
Is Nursing Home Demand Affected by the Decline in Age Difference Between Spouses?
}

\author{
Darius N. Lakdawalla ${ }^{1}$
}

\section{Robert F. Schoeni ${ }^{2}$}

\begin{abstract}
We investigate whether declines in the age difference between spouses has influenced widowhood and nursing home demand. We first use life-table methods to simulate the impact of the declining age gap on the risk of widowhood. We then use the Medicare Current Beneficiary Survey and the Census Public Use Microdata Samples to estimate the impact of widowhood, and other characteristics, on the probability of nursing home entrance. These help us estimate the impact of the declining age gap on nursing home use. We estimate that the decline in the difference in ages between spouses that took place between the birth cohorts of 1900 and 1955 may lower women's annual nursing home expenditures by about $\$ 1.4$ billion, but raise men's expenditures by about $\$ 600$ million.
\end{abstract}

RAND, 1700 Main Street, Santa Monica, CA 90407. darius@ rand.org.

Institute for Social Research, University of Michigan, 426 Thompson Street, Ann Arbor, MI 48109. bschoeni@umich.edu. 


\section{Introduction}

National expenditures on long-term care for the elderly are massive at almost $\$ 100$ billion annually (United States Congress Ways and Means Committee 2000). Roughly 40 percent of these costs are paid for directly by the elderly themselves, with virtually all of the remaining 60 percent, or almost $\$ 60$ billion, covered by the federal and state governments through Medicaid and Medicare. Moreover, given the aging of the population, particularly the growth in the number of elderly 85 and older who are at the greatest risk of using long-term care, projections suggest that long-term care expenditures will increase significantly over the next few decades.

In the search for ways to reduce costs, researchers have examined a variety of factors that influence nursing home use. This empirical literature has found that one of the primary determinants of nursing home use is marital status. While 48 percent of the elderly living in the community are widows, 67 percent of those in institutions are widows (Spector, Pezzin et al. 2000). Even after adjusting for age and a detailed set of health status measures, elderly without a spouse are much more likely to enter a nursing home (Kemper and Murtaugh 1991; Foley, Ostfeld et al. 1992; Steinbach 1992; Freedman, Berkman et al. 1994). It is argued that since spouses are quite often able to provide enough support for each other to prevent nursing home entry, being without a spouse elevates a person's risk of nursing home entry. Given the size of the effects of widow(er)hood, a natural question to ask is: what determines widow(er)hood? This study focuses on one such factor: the difference in ages between spouses. We lay out the reasons why the age gap between spouses may affect widow(er)hood and hence nursing home use. We then develop an empirical strategy to test whether projections of the nursing home population would be lower if the age gap, which is declining substantially across birth cohorts reaching old age between 1975 and 2025, were factored into such models.

\section{Long-term care in the United States}

Roughly speaking, medical care in the United States can be divided into short-term care and long-term care facilities. Hospitals function almost exclusively as short-term care facilities, focused on the treatment of acute disease. In general, they do not serve as inpatient rehabilitation centers for individuals recovering from acute conditions, or as facilities for people suffering from chronic long-term disabilities associated with oldage or infirmity. Patients in need of assistance for long periods of time (as a rule of thumb, this involves periods longer than 30 days), must seek care elsewhere. 
While hospitals are the primary facilities for short-term care, long-term care is provided by a variety of institutions and arrangements. As mentioned earlier, many chronically ill individuals remain at home, cared for by spouses, children, other family members, or friends (see, e.g., Stern 1995; Lakdawalla and Philipson 2002). Care at home by family members is sometimes supplemented by visits from home care providers, who provide some skilled nursing assistance (Ettner 1994; Pezzin, Kemper et al. 1996). Alternatively, however, patients too sick to remain at home (with or without home care visits) enter residential nursing home facilities, where they receive medical assistance from nurses and physicians, along with assistance for their daily needs (see, e.g., Garber and MaCurdy 1990). Of course, the reality is a bit more complex than these two alternatives alone can convey. Care at home and in a nursing home represent the two poles of a continuum of care, along which lie many intermediate options. For example, there are "assisted living" facilities with varying degrees of medical attention available. These are utilized by individuals who are, generally speaking, less disabled than nursing home residents. Nursing home care has a unique importance along this continuum though because its costs to the public sector are the most significant.

The presence of a living spouse, especially a younger (and healthier) spouse, substantially reduces the probability that a chronically ill individual will enter a nursing home, and correspondingly increases the probability that she will remain at home and receive care from a spouse, or remain in a less intensive care setting. Therefore, changing age differences could impact trends in the use of nursing homes. Moreover, trends in nursing home use have significant impacts on the US economy and on public budgets. Nursing homes alone account for more than $10 \%$ of medical expenditure in the US (OECD 1998), and as discussed in the introduction the US government pays for roughly $60 \%$ of nursing home expenditures (for more background on public payment, cf., Norton 1995). In particular, there are two major kinds of public medical assistance programs in the US: Medicare and Medicaid. Medicare is a federally funded program that provides coverage to individuals over age 65 , as well as disabled individuals under age 65. However, Medicare covers very few long-term care expenses. Medicaid, on the other hand, does cover long-term care expenses, and in fact accounts for the vast majority of public long-term care outlays. Medicaid is a jointly funded, Federal-State health insurance program for the poor. Within broad national guidelines that the Federal government provides, the states: establish their own eligibility rules; define the type, amount, duration, and scope of services; set rates of payment for services; and administer their own programs (Centers for Medicare and Medicaid Services web site, www.cms.gov, viewed on 4/9/2003). In contrast to state and federal outlays, private long-term care insurance is a relatively insignificant source of funding, accounting for well under 4 percent of total expenses (see, e.g., Garber and MaCurdy 1990). Out-ofpocket expenditures cover the remainder, roughly one-third of total expenditures. 


\section{Conceptual relationship between age gap and nursing home use}

The difference in ages between spouses may affect widowhood simply because of mortality. Consider two women of the same age, one whose husband is two years older and one whose husband is six years older. When these women are 75 years old, their husbands will be 77 and 83 respectively. Since survival to 83 is less likely than to 77 , the woman married to the older man is more likely to be a widow. For a given age of the wife, an increase in her husband's age raises the risk of widowhood and institutionalization. The opposite effect obtains for husbands. Consider two men of the same age, one who married a woman two years his junior and the other who married a woman six years his junior. When the men are 80 years old, their wives will be 78 and 74 , respectively. The man with the older wife is more likely to be a widower. Since husbands have typically been older than wives, a reduction in the spousal age gap across cohorts means that, for any given age of the husband, wives are older, more likely to leave the husband a widower, and thus elevate the husband's risk of nursing home entry. This does not imply that men will have higher levels of nursing home use than women, only that, all else equal, a reduction in the age gap - e.g., husbands are 1-2 years older instead of 4-5 years older- will make the gender imbalance in nursing populations smaller. That is, women will still account for the majority of nursing home residents, but the male proportion will increase somewhat.

To estimate the trend in spousal age gap across birth cohorts, we use the Public Use Microdata Samples of the 1940-1990 censuses. We constructed a sample of cohorts born between 1896 and 1955. For each cohort, we estimated the age difference between spouses for married women 35-44 years old. Although some marriage and divorce takes place after age 35, the gap in spouses' ages when they are 35 to 44 years old is probably a reasonable estimate of the gap that will exist between spouses as they begin to enter old age. We did not choose women older than 44 because mortality begins to become a factor at these ages for the oldest birth cohorts, and our objective is to examine these gaps as couples begin to enter old age and face elevated mortality risk. 


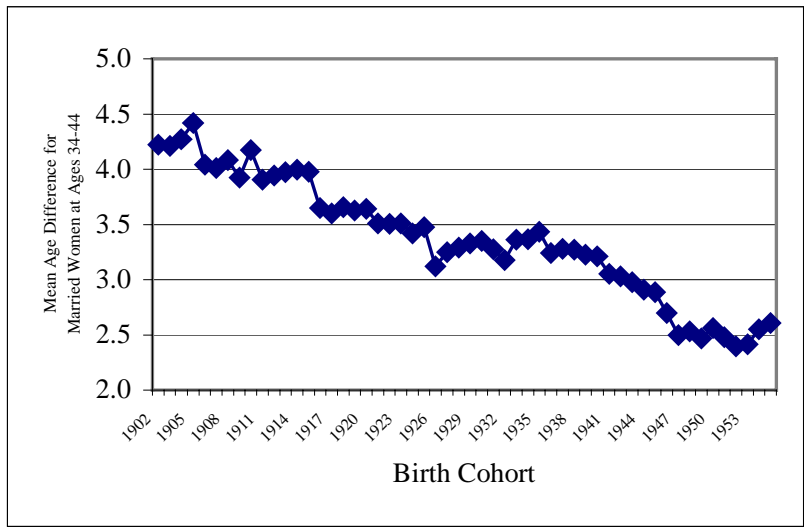

Figure 1: $\quad$ Mean Age Difference of Spouses by Birth Cohort.

Figure 1 shows that husbands tended to be almost 4.5 years older than their wives in the 1900 cohort, but just 2.5 years older by the 1950 cohort - today's 52 year-olds. If the age gap does affect nursing home use, it must already have had an impact: all of the cohorts born between 1900 and 1920 have already begun to hit the ages when nursing home entry escalates (roughly 75 to 85 years old); across these cohorts, the age gap shrank by about half a year. As the more recent birth cohorts begin to hit these older ages, Figure 1 implies a potential for a large, ongoing effect on nursing home entry. Over 30 years, the age gap dropped from 3.5 years (for the 1920 cohort) to 2.5 years (for the 1950 cohort). Trends in the difference in the median age at first marriage for men versus women demonstrate a similar pattern (US Bureau of the Census 1998).

In this paper, we present a method for determining whether the nursing home population would have been larger than it is today had the age gap between spouses not declined. Moreover, we determine whether future nursing home demand will be lower than expected because of continued reductions in the age gap. Past research on longterm care has focused on the impact of changing longevity, aging of the population, social support, caregiving opportunities, nursing home prices, marital status, and disability (cf., Garber and MaCurdy 1990; Stern 1995). While our goal is to determine whether this additional factor - change in the spousal age gap - influences long-run changes in nursing home demand, our conclusions do not diminish the important role of 
these other factors. In fact while our conclusions imply that the decline in the age gap will likely cause nursing home demand to be lower than expected, this effect will be offset by other factors and nursing home use will continue to increase substantially in the coming decades.

\section{Methods}

We investigate the effects of the changing age gap in three steps. First, using life table methods, we calculate the effect of the changing age difference on the risk of male and female widowhood. This allows us to calculate the change in the marriage rate-for different age and sex groups-that would have resulted from the changing difference in spousal ages. Second, we calculate the risk of nursing home entrance, conditional on age, sex, and marital status. Finally, we put the first two pieces of analysis together to calculate the effect of the age difference on nursing home entrance and the nursing home population.

We think of the entire population as broken up into various age-sex-marital status groups. The relative size of each group changes with the average age difference between spouses, as does the risk of nursing home entry faced by each group. Formally, therefore, we think of the nursing home population $\mathrm{NH}$ as depending on the average age difference $X$, according to:

$$
N H(X)=\sum_{i} N_{i}(X) p_{i}(X)
$$

The number of people in each group, $N_{i}$, and the probability that a person in group $i$ enters a nursing home, $p_{i}$, both change with $X$. The total effect of changes in the age difference must account for its effect on the composition of the population and the risk of nursing home entry within each population group.

\subsection{Age difference and the risk of widowhood}

According to Figure 1, the age difference changed rapidly across birth cohorts. To isolate the effect of a particular change in the age gap, we would ideally like to see an entire elderly population with the 4.5-year age gap, and compare its nursing home utilization to an entire elderly population with the 3.5-year gap. We can never observe these populations, but we can determine what they would look like by means of a simple simulation. This simulation reveals the long-run effect of lowering the age gap from its 1900 to 1955 level. 
We start by assuming that each cohort enters age 65 with a total population of unity; we net out the effects of population trends by assigning all cohorts the same population size. From the Current Population Survey (an annual demographic survey whose sampling frame is based on the US Census), we calculate actual population shares by sex and marital status for each cohort at age 65 . For example, if a cohort was observed to be 40 percent male and 60 percent female at age 65 , we say that it enters age 65 with 0.4 males and 0.6 females. In addition, if married men in the cohort are on average $X$ years older than their wives, each 65 year-old married man is assumed to have a $65-X$ year-old wife, and vice-versa.

Define $M W_{t}^{c}$ as the number of married women in cohort $c$ alive at age $t$ in our simulation. Similarly, define $M M_{t}^{c}$ as married men, $S W_{t}^{c}$ as single women, and $S M_{t}^{c}$ as single men. Given values for $M W_{65}^{c}, M M_{65}^{c}, S W_{65}^{c}$, and $S M_{65}^{c}$ (calculated as in the previous paragraph), each cohort is aged forward using life table data, as follows.

Denote by $S(a)$ the probability of surviving from age $a$ to age $a+1$; cohort-specific survival curves are from the Social Security Administration (US Department of Health and Human Services 1992). We use different survival curves for men and women, but to economize on notation, we refer to a single one. The transition equations are given by:

$$
\begin{aligned}
& M W_{t+1}^{c}=M W_{t}^{c}[S(t) S(t+X)] \\
& M M_{t+1}^{c}=M M_{t}^{c}[S(t) S(t-X)] \\
& S W_{t+1}^{c}=S W_{t}^{c}[S(t)]+M W_{t}^{c}[S(t)(1-S(t+X))] \\
& S M_{t+1}^{c}=S M_{t}^{c}[S(t)]+M M_{t}^{c}[S(t)(1-S(t-X))]
\end{aligned}
$$

The first two equations imply that the number of married people next period is equal to the current married population multiplied by the probability that both partners survive to the next period. The second two imply that the number of future single people is equal to the number of currently single people who survive, plus the number of currently married people who become widowed. This latter quantity is equal to the number of currently married people, multiplied by the probability that their spouses die, but they do not. We abstract from marriage and remarriage, which is uncommon for people over 65. The marriage rate for women 65 and older was just 1.9 per 1,000 unmarried women, a small fraction of the rate of 127.9 for women 25 to 29 years old. The rate for men 65 and older is higher at 12.5 per 1,000 , but it is still very small relative to the rate of 107 per 1,000 men ages 25 to 29 (Clark 1995). 
Using the initial population estimates and the transition equations, we calculate for each cohort the steady-state population at each age-sex-marital status. Differences in these populations across cohorts will be influenced both by the changing age gap, $X$, and by changes across cohorts in the probability of survival. Since we wish to focus on the effect of age differences alone, we apply the survival curve of the 1955 cohort to all other cohorts. This eliminates differences in longevity across cohorts and focuses our attention on the impact of age differences alone.

\subsection{Marriage and the risk of nursing home entry}

The next step is to transform the effects on population into effects on the number of nursing home residents. We need to calculate the proportion of person-years spent in nursing homes for each age-sex-marital status cell. These proportions are then multiplied by the number of people in each cell to estimate the growth in the annual nursing home population. One way to recover these proportions is to estimate the probability that a person will spend the year in a nursing home. To accomplish this goal, we will specify a logistic model of nursing home entry.

Suppose that on any given day of his life, individual $i$ faces a probability $p_{i}$ of spending that day in a nursing home, and a probability $1-p_{i}$ of spending it outside one. The advantages of this formulation are that it allows for exit from nursing home residence, and that it places more weight on people who are in nursing homes for a longer period of time. The disadvantage is that it treats each day in a nursing home as independent from the days preceding it. If person $i$ lives for $D_{i}$ days, the likelihood of spending $N_{i}$ of those days in a nursing home is given by $p_{i}{ }^{N_{i}}\left(1-p_{i}\right)^{D_{i}-N_{i}}$. A sample of $I$ individuals thus has the associated likelihood function:

$$
L=\prod_{i=1}^{I}\left(p_{i}\right)^{N_{i}}\left(1-p_{i}\right)^{D_{i}-N_{i}},
$$

We will model $p_{i}$ as a logistic probability, where

$$
p_{i}=\frac{\exp \left(X_{i}^{\prime} \beta\right)}{1+\exp \left(X_{i}^{\prime} \beta\right)},
$$

and $X_{i}$ is a column vector of characteristics for individual $i$.

Given the maximum likelihood parameters $\beta$, we estimate for every individual in the sample an estimated probability of nursing home entrance, $p_{i}$. By averaging these fitted values within each age-sex-marital status cell, we calculate the average 
probability of nursing home entrance for each cell. This is equal to the expected proportion of people within each cell who will enter nursing homes. Applying this proportion to our estimates of the population within each cell, we can construct estimates of the nursing home population for each cohort and each cell.

\subsubsection{Data}

To estimate the probability of nursing home entry, we use data from the 1992-1996 Medicare Current Beneficiary Surveys (MCBS) Cost and Use Files. While data are available for 1997-99, they are not comparable to the earlier years, because of a difference in the way nursing home residents are asked about their disability status. By estimating the risk of nursing home entry in a single data set, we implicitly hold technology fixed at its 1990s levels to focus on the effects of the changing age gap. In practice, however, the risk of nursing home entry has remained a fairly stable function of age, marriage, and disability rates, even over periods of substantial change in the utilization of nursing homes and the availability of home health care and other alternatives to nursing homes (Lakdawalla and Philipson 2002).

The MCBS is a panel data set, every year of which is a weighted sample of the Medicare population. Since all individuals over age 65 are on Medicare, it can also be used as a nationally representative sample of individuals over 65; even though it is a panel, the sample is refreshed annually to correct for attrition and produce a nationally representative sample. Significantly, the MCBS samples all individuals, both institutionalized and non-institutionalized. The oldest-old (over 85 years of age) are oversampled. The MCBS collects age, sex, marital status, and disability status, where disability is measured as the number of limitations on Activities of Daily Living (ADL). There are six ADL limitations in total, which consist of difficulties with: bathing, dressing, eating, using the toilet, getting up from a chair, and walking.

For our purposes, the MCBS was the best available data set, although it did involve some trade-offs. Clearly, we need a data set that includes the entire elderly population, including those in nursing homes. This narrows the field considerably. The major nationally representative data sets satisfying these criteria are the US Census, and the associated annual Current Population Surveys (CPS), along with the Health and Retirement Study (HRS), and its sister, Asset and Health Dynamics among the OldestOld (AHEAD). The CPS was eliminated because it does not include the institutional population. The Census was eliminated because it lacks the necessary detailed information about health conditions. For their part, the HRS and AHEAD are cohortbased panel studies with detailed health information. However, their initial samples were drawn entirely from the non-institutionalized population, and the only individuals 
in nursing homes were those who enter during the 8-year life of the panel. As a result, these data sets systematically understate the mean risk of nursing home admission. This problem is exacerbated by the fact that HRS/AHEAD often do not collect information on nursing home stays for people who die between waves of the survey: since nursing homes represent the last source of medical care for many terminally ill patients, this will further bias down estimates of nursing home risk. The MCBS, on the other hand, does report this information for decedents, either from administrative records or proxy interviews. Therefore, it allows us to construct an accurate estimate of nursing home risk. The key drawback of the MCBS is its nature as an individual-based survey, rather than a family-based survey. Therefore, we have very limited information on the spouses of respondents, and most significantly, we do not have data on spousal dates of birth. The HRS and AHEAD, on the other hand, do have some information on spousal ages, because they are family-based surveys. However, even for these data sets, spousal date of birth is available only for living spouses. We would have had to impute the information for deceased spouses. Since about $40 \%$ of the US population over age 65 is widowed, this is a significant issue. In sum, we chose the MCBS and its complete data on nursing home risk, over the HRS/AHEAD and its incomplete data on spousal ages. As a result, we impute spousal ages for the MCBS sample according to the procedure described below.

We topcode age at 95 , because the MCBS sample is too sparse above this age to estimate smooth age-specific incidences of nursing home entry. From the MCBS, we need characteristics that influence an individual's decision to enter a nursing home. Two of the most important determinants of nursing home demand are an individual's health and the relative price of a nursing home, compared to family-based care. In addition to marital status, other variables affecting the relative price of nursing home care are the person's number of living children and ethnic group (Black, Hispanic, or other). Ethnicity may proxy for the availability of family and community caregivers and may be correlated with the price of community-based care. Health status is measured by several sets of dummy variables. We use dummies for the number of ADL limitations; these are interacted with marriage because spousal care may be a less effective substitute for highly disabled people. In addition, we use dummies for education group (less than a high school degree, a high school degree, less than a college degree, a college degree, or more than a college degree), income group (annual income less than $\$ 10,000$, between $\$ 10,000$ and $\$ 30,000$, between $\$ 30,000$ and $\$ 50,000$, and above $\$ 50,000$ ), and the individual's illness history. In particular, we have data on whether the individual has ever been diagnosed with: high blood pressure, coronary heart disease, Alzheimer's disease, Parkinson's disease, stroke, diabetes, a broken hip, emphysema, cancer (as well as specific types of cancer), partial paralysis, past amputation, osteoporosis, and psychological conditions. 
Annual summary statistics for the MCBS are presented in Table 1. The summary statistics are weighted in order to represent the entire population over the age of 65 . The table indicates that 41 percent of the population is male, and the median age is around 75. Relatively few people have more than a high school education or more than $\$ 30,000$ in annual income. About half are married, and over 30 percent have an ADL limitation of some kind. The prevalence of ADLs is a bit higher in the MCBS than in other surveys, primarily due to a difference in the question about walking limitations. The MCBS asks respondents if they have trouble walking 2-3 blocks, whereas other surveys (such as the National Health Interview Survey) tend to ask if they have trouble getting around inside their house. High blood pressure and heart disease are the most common ailments among the MCBS population. About half the population has been diagnosed with high blood pressure at some point in their lives, and roughly the same proportion has been diagnosed with heart disease.

We would also like to know if having an older spouse has any direct effects on the risk of nursing home entry, holding constant one's age and marital status. There are at least two reasons to expect a relationship. First, among currently married people, having a younger spouse may afford better protection against the risk of nursing home entry, if younger people are better able to care for their spouses in the event of illness. Second, among ever-married people, there may be a selection effect: those who marry younger spouses may be unobservably healthier and thus less likely to enter nursing homes. We can distinguish between these two effects by examining the effect of spousal age on currently married people, and on widowed people. 
Table 1: $\quad$ Annual Summary Statistics for the MCBS Population

\begin{tabular}{|c|c|c|c|c|c|c|c|c|c|c|}
\hline & \multicolumn{2}{|l|}{1992} & \multicolumn{2}{|l|}{1993} & \multicolumn{2}{|l|}{1994} & \multicolumn{2}{|l|}{1995} & \multicolumn{2}{|l|}{1996} \\
\hline & Mean & St Dv & Mean & St Dv & Mean & St Dv & Mean & St Dv & Mean & St Dv \\
\hline Observations & 10554 & & 10152 & & 10516 & & 9930 & & 9823 & \\
\hline $\begin{array}{l}\text { Statewide Proportion of Medicaid } \\
\text { Eligible }\end{array}$ & 0.11 & 0.05 & 0.11 & 0.05 & 0.12 & 0.05 & 0.12 & 0.05 & 0.11 & 0.05 \\
\hline Male & 0.41 & 0.49 & 0.41 & 0.49 & 0.41 & 0.49 & 0.41 & 0.49 & 0.41 & 0.49 \\
\hline Black & 0.08 & 0.28 & 0.08 & 0.28 & 0.08 & 0.27 & 0.08 & 0.27 & 0.08 & 0.27 \\
\hline Hispanic & 0.05 & 0.21 & 0.05 & 0.22 & 0.05 & 0.22 & 0.05 & 0.22 & 0.05 & 0.22 \\
\hline Ever Smoked? & 0.58 & 0.49 & 0.60 & 0.49 & 0.62 & 0.49 & 0.62 & 0.49 & 0.62 & 0.49 \\
\hline Age 85 and Over & 0.12 & 0.32 & 0.12 & 0.33 & 0.13 & 0.33 & 0.13 & 0.34 & 0.13 & 0.33 \\
\hline Age 80 to 84 & 0.14 & 0.34 & 0.14 & 0.34 & 0.14 & 0.35 & 0.14 & 0.35 & 0.15 & 0.35 \\
\hline Age 75 to 79 & 0.20 & 0.40 & 0.20 & 0.40 & 0.20 & 0.40 & 0.20 & 0.40 & 0.21 & 0.40 \\
\hline Age 70 to 74 & 0.25 & 0.44 & 0.26 & 0.44 & 0.27 & 0.44 & 0.26 & 0.44 & 0.28 & 0.45 \\
\hline Number of Children Living & 2.68 & 2.26 & 2.74 & 2.27 & 2.78 & 2.25 & 2.81 & 2.26 & 2.80 & 2.24 \\
\hline Education less than High School & 0.43 & 0.50 & 0.43 & 0.49 & 0.41 & 0.49 & 0.41 & 0.49 & 0.39 & 0.49 \\
\hline Education: Some College & 0.13 & 0.34 & 0.13 & 0.34 & 0.14 & 0.34 & 0.14 & 0.35 & 0.15 & 0.35 \\
\hline Education: College Degree & 0.08 & 0.28 & 0.08 & 0.28 & 0.08 & 0.28 & 0.09 & 0.28 & 0.09 & 0.29 \\
\hline Education: Post-College & 0.05 & 0.21 & 0.05 & 0.21 & 0.05 & 0.22 & 0.05 & 0.21 & 0.05 & 0.21 \\
\hline Education & & & & & & & & & & \\
\hline Married & 0.54 & 0.50 & 0.56 & 0.50 & 0.56 & 0.50 & 0.53 & 0.50 & 0.53 & 0.50 \\
\hline Income: $\$ 10,000$ to $\$ 30,000$ & 0.50 & 0.50 & 0.51 & 0.50 & 0.50 & 0.50 & 0.51 & 0.50 & 0.52 & 0.50 \\
\hline Income: $\$ 30,000$ to $\$ 50,000$ & 0.11 & 0.31 & 0.12 & 0.32 & 0.13 & 0.34 & 0.13 & 0.34 & 0.14 & 0.35 \\
\hline Income: Above $\$ 50,000$ & 0.05 & 0.21 & 0.05 & 0.22 & 0.05 & 0.22 & 0.06 & 0.24 & 0.07 & 0.26 \\
\hline$A D L s=1$ & 0.14 & 0.34 & 0.12 & 0.33 & 0.11 & 0.32 & 0.11 & 0.32 & 0.11 & 0.31 \\
\hline$A D L s=2$ & 0.07 & 0.25 & 0.07 & 0.25 & 0.07 & 0.25 & 0.06 & 0.24 & 0.06 & 0.24 \\
\hline$A D L s=3$ & 0.04 & 0.19 & 0.04 & 0.19 & 0.04 & 0.19 & 0.04 & 0.19 & 0.03 & 0.18 \\
\hline$A D L s=4$ & 0.03 & 0.17 & 0.03 & 0.17 & 0.03 & 0.17 & 0.03 & 0.17 & 0.03 & 0.16 \\
\hline$A D L s=5$ & 0.04 & 0.19 & 0.04 & 0.19 & 0.04 & 0.19 & 0.04 & 0.19 & 0.04 & 0.18 \\
\hline$A D L s=6$ & 0.04 & 0.19 & 0.04 & 0.19 & 0.04 & 0.19 & 0.04 & 0.19 & 0.04 & 0.20 \\
\hline High Blood Pressure & 0.51 & 0.50 & 0.53 & 0.50 & 0.54 & 0.50 & 0.54 & 0.50 & 0.54 & 0.50 \\
\hline Heart Disease & 0.42 & 0.49 & 0.44 & 0.50 & 0.44 & 0.50 & 0.44 & 0.50 & 0.42 & 0.49 \\
\hline Alzheimer's Disease & 0.04 & 0.20 & 0.05 & 0.21 & 0.05 & 0.22 & 0.05 & 0.22 & 0.06 & 0.23 \\
\hline Parkinson's Disease & 0.02 & 0.14 & 0.02 & 0.13 & 0.02 & 0.13 & 0.02 & 0.12 & 0.02 & 0.14 \\
\hline Stroke & 0.11 & 0.31 & 0.12 & 0.32 & 0.12 & 0.33 & 0.13 & 0.33 & 0.13 & 0.33 \\
\hline Diabetes & 0.16 & 0.37 & 0.17 & 0.38 & 0.18 & 0.38 & 0.17 & 0.38 & 0.16 & 0.37 \\
\hline Broken Hip & 0.05 & 0.22 & 0.05 & 0.22 & 0.06 & 0.23 & 0.05 & 0.23 & 0.05 & 0.22 \\
\hline Emphysema & 0.13 & 0.34 & 0.14 & 0.35 & 0.15 & 0.35 & 0.15 & 0.35 & 0.14 & 0.35 \\
\hline Cancer (except skin) & 0.18 & 0.39 & 0.19 & 0.39 & 0.20 & 0.40 & 0.20 & 0.40 & 0.19 & 0.39 \\
\hline Partial Paralysis & 0.07 & 0.26 & 0.07 & 0.26 & 0.07 & 0.26 & 0.06 & 0.24 & 0.06 & 0.23 \\
\hline Amputee & 0.01 & 0.11 & 0.01 & 0.11 & 0.01 & 0.10 & 0.01 & 0.11 & 0.01 & 0.10 \\
\hline Osteoporosis & 0.09 & 0.29 & 0.10 & 0.30 & 0.11 & 0.31 & 0.11 & 0.32 & 0.12 & 0.33 \\
\hline Psychological Disorders & 0.04 & 0.20 & 0.05 & 0.21 & 0.05 & 0.22 & 0.05 & 0.22 & 0.05 & 0.22 \\
\hline
\end{tabular}

Since the MCBS does not collect data on age of spouse, we impute it using data from the 1960 Census Public Use Microdata Sample (PUMS). The decennial United States Censuses represent complete population samples of the US. For a random, nationally representative $1 \%$ subsample of the complete Census population, the Census Bureau administers a detailed questionnaire, with information about income, education, marital status, family composition, area of residence, and a whole host of other variables. This 
questionnaire, and the data collected from it, forms the basis of the PUMS data set, which is available in every Census year. Since most demographic surveys (such as the Current Population Surveys, and National Health Interview Surveys) are based on the sampling information collected in the Census, the Census PUMS sample represents one of the most reliably representative samples, for use in detailed demographic analyses of the US population. It is the "gold standard" for analyses of population age structure and family composition in the US.

We constructed a sample of every married person in the 1960 PUMS, containing the variables: own age, spouse's age, dummies for state of residence, a dummy for metropolitan residence status, dummies for family income decile, dummies for race (white, black, or other), dummies for educational attainment (no schooling, 1-4 years of schooling, 5-8 years of schooling, $9^{\text {th }}$ grade, $10^{\text {th }}$ grade, $11^{\text {th }}$ grade, $12^{\text {th }}$ grade, college attendee, and college graduate), and veteran status.

To impute the age of husbands, we take all 35-45 year-old married women in the 1960 Census - this corresponds roughly to the birth cohorts that are 65 to 75 years old in the MCBS sample - and regress the woman's age on her husband's age, a dummy for metropolitan status, dummies for state of residence, family income dummies, race dummies, and educational attainment dummies. Similarly, to impute the age of wives, we take all 35-45 year-old married men in the 1960 Census and perform the same procedure. We do not choose people above age 45 because a significant proportion of the earlier cohorts died by their late 40s and early 50s. The results of these regressions are displayed in Table 2. Not surprisingly, age of spouse goes up nearly one-for-one with an individual's age. The table makes clear that richer, better educated, and urban couples tend to exhibit smaller age differences, in the sense that the husband is on average younger. This empirical result is not directly consistent with the Bergstrom and Bagnoli (1993) theory of marriage, in which the most desirable males wait longer to get married than the least desirable. However, the Bergstrom and Bagnoli framework also suggests that the gap is smaller when men and women have less distinct economic roles within the household. This may occur more frequently for educated couples. 
Demographic Research - Volume 8, Article 10

Table 2: $\quad$ Imputations of Spouse's Age for married 35-45 year-olds in 1960 Census.

\begin{tabular}{|c|c|c|c|c|}
\hline & \multicolumn{2}{|c|}{ Husband's Age } & \multicolumn{2}{|c|}{ Wife's Age } \\
\hline & Coeff. & T-Statistic & Coeff. & T-Statistic \\
\hline Own Age & $1.01 *$ & 160.08 & 0.90 * & 162.15 \\
\hline Metro Residence & $-0.17 *$ & -3.87 & 0.02 & 0.57 \\
\hline Family Income Decile 2 & $-0.83 *$ & -9.75 & $0.19 *$ & 2.63 \\
\hline Family Income Decile 3 & $-1.10 *$ & -12.98 & $0.27 *$ & 3.69 \\
\hline Family Income Decile 4 & $-1.45 *$ & -17.38 & $0.52 *$ & 7.31 \\
\hline Family Income Decile 5 & $-1.62 *$ & -17.92 & $0.62 *$ & 8.53 \\
\hline Family Income Decile 6 & $-1.49 *$ & -17.30 & $0.86 *$ & 11.64 \\
\hline Family Income Decile 7 & $-1.51 *$ & -17.18 & $0.91 *$ & 12.48 \\
\hline Family Income Decile 8 & $-1.31 *$ & -15.94 & $1.08 *$ & 14.56 \\
\hline Family Income Decile 9 & $-1.19 *$ & -12.25 & $1.24 *$ & 17.03 \\
\hline Family Income Decile 10 & $-0.82 *$ & -9.04 & $1.27 *$ & 15.90 \\
\hline Black & 0.28 * & 3.97 & $-0.26 *$ & -4.27 \\
\hline Other Race & 0.49 & 1.89 & $-1.57 *$ & -7.15 \\
\hline Grades 1-4 & $-1.61 *$ & -5.50 & $-0.74 *$ & -3.38 \\
\hline Grades 5-8 & $-2.12 *$ & -7.76 & $-0.68 *$ & -3.27 \\
\hline 9th Grade & $-2.41 *$ & -8.63 & -0.56 * & -2.62 \\
\hline 10th Grade & $-2.57 *$ & -9.29 & -0.48 & -2.28 \\
\hline 11th Grade & $-2.68 *$ & -9.59 & $-0.60 *$ & -2.80 \\
\hline 12th Grade & $-3.12 *$ & -11.45 & -0.51 & -2.46 \\
\hline College Attendee & $-3.25 *$ & -11.73 & $-0.57 *$ & -2.68 \\
\hline College Graduate & $-3.64 *$ & -12.95 & $-0.94 *$ & -4.43 \\
\hline Constant & 7.31 * & 18.69 & $-0.45 *$ & -12.45 \\
\hline Veteran Status & . & . & 1.24 * & 3.86 \\
\hline Observations & 87278 & & 82879 & \\
\hline R-Squared & 0.251 & & 0.268 & \\
\hline
\end{tabular}

All of the variables in Table 2 are available in the MCBS. Therefore, we use these regressions to forecast, for every person in the MCBS who has ever been married, how old their spouse would have been when they were 40 years old. From this, we calculate what the current age of his or her spouse would be at the time of observation in the MCBS data. 


\subsubsection{Statistical model}

Given the MCBS data and the imputed age of spouse, we estimate a logistic model:

$$
X_{i}^{\prime} \beta=\beta_{1}+\beta_{2} \text { Age }_{i}+\beta_{3} \operatorname{Marr}_{i}+\beta_{4} \operatorname{Marr}_{i}^{*} \Delta_{i}+\beta_{5} \operatorname{EvMarr}_{i}^{*} \Delta_{i}+Q_{i}^{\prime} \beta_{6}+\varepsilon_{i}
$$

The variables Marr $_{i}$ and $E v M a r r_{i}$ are dummies for whether the individual is married or has ever been married. The age difference between spouses is $\Delta_{i}$, and is always defined by the person's own age minus the spouse's age. Without loss of generality, $\Delta_{i}$ is set to zero for the never-married. $\beta_{2}$ measures the effect of age on the risk of nursing home entrance, and we expect it to be positive. $\beta_{3}$ measures the effect of marriage; to the extent that spouses function as a substitute for nursing home care, we expect it to be negative. (It is also possible that marriage signals better health: see e.g., Ebrahim, Wannamethee et al. 1995; Lillard and Panis 1996.) $\beta_{4}$ measures the effect of age difference for currently married people. If having a younger spouse affords better protection against nursing home entry, we expect it to be negative. $\beta_{5}$, on the other hand, measures the effect on ever-married people of the age difference, but controlling for observable health and marital status. We separate the effect of age differences for widowed and married people, because the age difference affects the availability of spousal care for married people, but not for widowed people. A married women with a very old husband may not be able to receive care from him as readily as one with a younger husband. A widowed woman, on the other hand, will not receive care from a spouse regardless of the age difference. $\beta_{5}$ will pick up the indirect effect of age difference on unobserved health, and it is identified by variation in spouse's age among those who are widowed. This is not to say that $\beta_{5}$ measures the overall effect of health, only that portion of unobserved health that may be correlated with the age difference. Since these people no longer have a spouse, it is unaffected by the spouse's ability to provide care at home, and represents instead a measure of the surviving spouse's health. Finally, $Q_{i}$ represents a vector of other characteristics, including ADLs, sex, race, income category, and educational attainment.

An important simplification made by this model is the linearity of the age difference and marriage effects. A one-year increase in the age gap is presumed to have the same effect no matter what its starting point. This assumption was not found to affect our ultimate results of interest: we introduced squared and cubic terms in $\Delta_{i}$ but found they had negligible effects on our estimated effect of the changing age gap on the total nursing home population. This is because the largest impacts of the age difference 
are on the composition of the population, rather than on its risk of nursing home entry. We also assume that the effect of marriage itself is linear. The coefficient $\beta_{3}$ measures the difference in risk between a never married person and a married person whose spouse is of identical age. It is the effect of marriage abstracting from any spousal age difference. Linearity means this effect is assumed to be the same for those with older (or younger) spouses as it is for those with identically aged spouses. We tested the robustness of this assumption by creating one-year categorical variables for the age difference (i.e., there was a dummy variable for a difference of -2 , one for a difference of -1 , one for a difference of zero, and so on) and fully interacting these with the marriage variable. We found similar results with this more flexible specification.

Finally, due to data constraints, the model makes some other simplifications by ruling out the effect of nursing home prices, abstracting from interactions among disease conditions, and abstracting from the possibility that some people are so sick that they die before entering a nursing home. Recognizing these limitations, we perform sensitivity analysis in Section 5.3 designed to show the possible impact of errors in estimating the risk of nursing home entrance.

\subsection{Age difference and the nursing home population}

The final step is to calculate the size of the nursing home population for each cohort, and each age-sex-marital status cell. Given the size of the population in each age-sexmarital status cell, it remains only to calculate the risk of nursing home entrance. To do this, we assume that, within an age-sex-marital status cell, every cohort is identical to the MCBS sample in every respect, except in its age difference between spouses. Therefore, to calculate the risk of nursing home entrance for a particular cohort $c$, that has an average age difference $X$, we keep the MCBS sample as is, but we assign every ever-married person in it the age difference $X$. Using these characteristics, we then compute the average risk of nursing home entrance within an age-sex-marital status cell. This represents the cell-specific risk of nursing home entrance that cohort $c$ would face as a result of its age difference $X$, and holding all other characteristics constant at their MCBS levels.

We multiply these cell-specific risks by the cohort's cell-specific population; this yields the cell-specific nursing home population. To understand this procedure more formally, let $N_{s m t}$ denote the number of people of sex $s$, marital status $m$, and age $t$. Denote by $p_{s m t}$ the corresponding probability of nursing home entrance. The populations $N$ depend on the age gap between spouses, $X_{c}$, that is specific to each cohort $c$; we calculated these populations, as functions of the age gap, in the 
simulations described in Section 4.1. The entrance probabilities also depend on the age gap, as well as other characteristics of the cell, such as its average disability, race, and so on. We will refer to these other characteristics using the vector $\vec{Y}$, which represents the characteristics of the MCBS population. These definitions allow us to write the nursing home population as a function of the age gap between spouses:

$$
N H\left(X_{c}\right)=\sum_{s, m, t} N_{s m t}\left(X_{c}\right) p_{s m t}\left(X_{c} ; \vec{Y}\right)
$$

Equation 4 demonstrates the relationship between the nursing home population and the age gap between spouses.

\section{Results}

\subsection{Age difference and the risk of widowhood}

Figure 2 shows the results for the 1900 and 1955 birth cohorts of the simulation methods presented in Section 4.1. Since we are using a constant survival curve, the effects in the figure represent only the effect of changing age differences, not changing longevity. The age gap fell from 4.43 years among the 1900 birth cohort to 2.61 for the 1955 birth cohort. The top panels represent the married populations, while the bottom panels represent the unmarried. The left panels represent men, while the right panels represent women. 

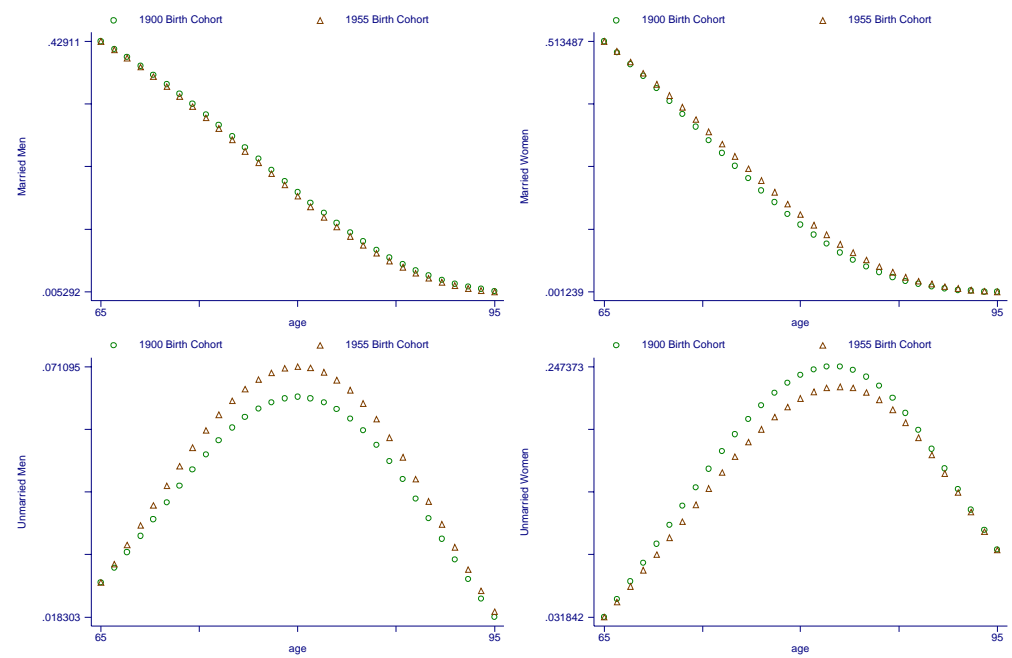

Figure 2: $\quad$ Projected Effect of Age Differences on the Married and Unmarried Populations

The declining age gap means that women find themselves married to relatively younger men. Therefore, as Figure 2 shows, across cohorts, the population of married women rises by 6.13 percent; the unmarried female population falls by 6.80 percent; the married male population falls by 2.45 percent; and the unmarried male population rises by 8.96 percent. We will see that, given the size of the relationship between marriage and nursing home risk, these changes have significant impacts on nursing home populations and total nursing home expenditures.

\subsection{Marriage and the risk of nursing home entry}

Section 4.2. presented our methods for estimating the effect of population changes on the nursing home population. Table 3 presents the associated results of our maximum likelihood estimation procedure. The table shows coefficients, robust z-statistics, and marginal effects for each variable. The marginal effect is computed as the average marginal effect for each individual in the data set and should be interpreted as the expected value of the marginal effect. As expected, married people are less likely to 
enter nursing homes, and the effect of marriage is stronger for those with younger spouses. However, the effect of marriage is attenuated for highly disabled people, according to the interaction terms between ADLs and marriage. This is understandable, since it is harder for a spouse to care for a highly disabled mate than a less disabled one. In keeping with the importance of alternative caregivers, people who have more living children are less likely to enter a nursing home. The effect of spouse's age difference on those who have ever been married, on the other hand, is negligible. Of course, since we were forced to impute our data on age difference, our evidence on this point should not be taken as conclusive. In addition, the probability of nursing home entrance goes down with income - probably because income is correlated with unobserved health, and because elderly people spend down their assets in order to become eligible for Medicaid-and it goes up with disability and disease.

There are a few anomalies here though: having ever smoked, high blood pressure, osteoporosis, or being partially paralyzed are actually negatively correlated with nursing home entrance. One possible explanation for the smoking effect or the partial paralysis effect is mortality selection: those who survive into their old-age with these conditions are likely to be quite robust. It is less clear how to interpret the effects of high blood pressure and osteoporosis. It may be pertinent that these are relatively mild, harder to diagnose conditions. Those people who recognize their illness may actually be the ones who are most vigilant about their health. This factor is made more important, because controlling for health status, a larger percentage of the variation in disease conditions-compared with the unconditional variation-is due to differential diagnosis and a smaller percentage due to differences in underlying health status. 
Demographic Research - Volume 8, Article 10

Table 3: $\quad$ Estimating the Probability of Nursing Home Entry in the MCBS.

\begin{tabular}{|c|c|c|c|}
\hline & Coefficient & Z-Statistic & Marginal Effect \\
\hline Male & 0.36 * & 2.00 & 0.0090 \\
\hline Married & $-1.81 *$ & -7.03 & -0.0449 \\
\hline Married * Age Difference & -0.06 * & -2.33 & -0.0014 \\
\hline Ever Married * Age Difference & 0.01 & 0.20 & 0.0001 \\
\hline Age $70-74$ & 0.36 * & 2.22 & 0.0089 \\
\hline Age $75-79$ & 0.65 * & 4.34 & 0.0161 \\
\hline Age $80-84$ & 0.82 * & 5.85 & 0.0202 \\
\hline Age $85+$ & 1.12 * & 8.06 & 0.0278 \\
\hline Black & -0.30 * & -2.75 & -0.0075 \\
\hline Number Children Living & -0.42 * & -17.14 & -0.0105 \\
\hline Less than High School & -0.16 * & -2.15 & -0.0039 \\
\hline College Attendee & -0.29 * & -2.67 & -0.0072 \\
\hline College Graduate & $-0.47 *$ & -3.47 & -0.0117 \\
\hline Post-College Education & -0.32 & -1.47 & -0.0079 \\
\hline Less than $\$ 30,000$ Income & $-0.80 *$ & -11.60 & -0.0199 \\
\hline Income of $\$ 30,000-\$ 49,999$ & $-0.87 *$ & -5.39 & -0.0216 \\
\hline Income of $\$ 50,000_{+}$ & -1.11 * & -4.48 & -0.0275 \\
\hline $1 \mathrm{ADL}$ & 1.09 * & 7.43 & 0.0271 \\
\hline 2 ADLs & 1.90 * & 13.81 & 0.0472 \\
\hline 3 ADLs & 2.42 * & 16.67 & 0.0600 \\
\hline $4 \mathrm{ADLS}$ & 2.41 * & 16.72 & 0.0597 \\
\hline $5 \mathrm{ADLS}$ & 3.42 * & 26.60 & 0.0849 \\
\hline 6 ADLs & 3.65 * & 26.99 & 0.0905 \\
\hline $1 \mathrm{ADL}$ * Married & 0.98 * & 2.71 & 0.0242 \\
\hline 2 ADLs * Married & 1.09 * & 3.37 & 0.0271 \\
\hline 3 ADLs * Married & 1.02 * & 2.86 & 0.0254 \\
\hline 4 ADLs * Married & 1.05 * & 2.95 & 0.0261 \\
\hline 5 ADLs * Married & 1.29 * & 4.27 & 0.0320 \\
\hline 6 ADLs * Married & 1.46 * & 5.10 & 0.0363 \\
\hline Ever Smoked & -0.42 * & -6.19 & -0.0105 \\
\hline High Blood Pressure & -0.33 * & -5.26 & -0.0081 \\
\hline Heart Disease & 0.30 * & 4.84 & 0.0076 \\
\hline Alzheimer's Disease & 1.84 * & 25.04 & 0.0456 \\
\hline Parkinson's Disease & -0.03 & -0.17 & -0.0006 \\
\hline Stroke & 0.30 * & 4.05 & 0.0075 \\
\hline Diabetes & 0.10 & 1.37 & 0.0025 \\
\hline Hip Fracture & 0.49 * & 6.69 & 0.0121 \\
\hline Emphysema & -0.01 & -0.08 & -0.0002 \\
\hline Cancer & 0.05 & 0.72 & 0.0013 \\
\hline Partially Paralyzed & 0.32 * & 3.73 & 0.0079 \\
\hline Amputee & -0.59 * & -2.71 & -0.0146 \\
\hline Osteoparosis & -0.75 * & -9.05 & -0.0185 \\
\hline Psychological Disorder & 1.03 * & 11.28 & 0.0255 \\
\hline Constant & $-4.57 *$ & -22.92 & -0.1135 \\
\hline
\end{tabular}

Notes:

Z-statistics are robust.

* indicates significance at the $5 \%$ level. 
Using the coefficients in Table 3, we can now calculate the average risk of nursing home entrance within age-sex-marital status cells, by calculating the risk of entrance for each individual, and then averaging these risks within age-sex-marital status cells. This then allows us to determine how many married and unmarried men and women would require nursing home care, given the current state of health technology. It is worth emphasizing again that by estimating the risk of nursing home entrance from a 1990s data set, we are holding fixed health technology at its recent level, and removing it as a factor in determining nursing home demand.

\subsection{Age difference and the nursing home population}

For each cohort $c$, Table 4 summarizes the quantity $\frac{N H\left(X_{c}\right)-N H\left(X_{1900}\right)}{N H\left(X_{1900}\right)}$, the percentage change in the nursing home population caused by the changing age gap between spouses, relative to the 1900 birth cohort. To put these percentage changes into context, we have also calculated the absolute change in nursing home expenditures implied by the change in population, based on the current cost of a nursing home$\$ 50,000$ per year-and the 1997 nursing home population composition calculated from the MCBS. The $\$ 50,000$ estimate is taken from the Green Book (United States Congress Ways and Means Committee 2000), and checked against estimates from the National Nursing Home Survey (NNHS). Calculating total nursing home patient revenues and bed-days from the 1995 NNHS reveals an average price of $\$ 35,330$ per year in 1995. Using the 1986 NNHS reveals a figure of $\$ 18,100$ per year in 1986. Using the implied annual rate of inflation, we extrapolated the 1995 figure to obtain an estimate of $\$ 51,100$ per year in 2000 . 
Table 4: $\quad$ The effect of the changing age difference of spouses on nursing home populations and expenditures

\begin{tabular}{|c|c|c|c|c|c|c|c|c|c|c|c|}
\hline \multicolumn{6}{|c|}{ Percentage Change in Nursing Home Population } & \multicolumn{6}{|c|}{ Absolute Change in Nursing Home Expenditures (\$millions) } \\
\hline $\begin{array}{l}\text { Females } \\
\text { Married }\end{array}$ & Unmarried & All & $\begin{array}{l}\text { Males } \\
\text { Married }\end{array}$ & Unmarried & All & $\begin{array}{l}\text { Females } \\
\text { Married }\end{array}$ & Unmarried & All & $\begin{array}{l}\text { Males } \\
\text { Married }\end{array}$ & Unmarried & All \\
\hline $0.0 \%$ & $0.0 \%$ & $0.0 \%$ & $0.0 \%$ & $0.0 \%$ & $0.0 \%$ & 0 & 0 & 0 & 0 & 0 & 0 \\
\hline $2.5 \%$ & $-0.6 \%$ & $-0.3 \%$ & $-0.8 \%$ & $1.2 \%$ & $0.4 \%$ & 115 & -301 & -186 & -61 & 146 & 85 \\
\hline $7.7 \%$ & $-1.9 \%$ & $-0.8 \%$ & $-2.7 \%$ & $3.9 \%$ & $1.2 \%$ & 356 & -928 & -572 & -193 & 461 & 268 \\
\hline $9.3 \%$ & $-2.3 \%$ & $-1.0 \%$ & $-3.2 \%$ & $4.8 \%$ & $1.5 \%$ & 433 & $-1,128$ & -695 & -235 & 561 & 326 \\
\hline $10.6 \%$ & $-2.7 \%$ & $-1.1 \%$ & $-3.7 \%$ & $5.4 \%$ & $1.7 \%$ & 493 & $-1,283$ & -790 & -266 & 636 & 370 \\
\hline $9.7 \%$ & $-2.5 \%$ & $-1.0 \%$ & $-3.4 \%$ & $5.0 \%$ & $1.6 \%$ & 453 & $-1,179$ & -726 & -245 & 586 & 341 \\
\hline $12.1 \%$ & $-3.0 \%$ & $-1.3 \%$ & $-4.1 \%$ & $6.1 \%$ & $1.9 \%$ & 560 & $-1,456$ & -896 & -301 & 719 & 418 \\
\hline $15.4 \%$ & $-3.9 \%$ & $-1.6 \%$ & $-5.2 \%$ & $7.8 \%$ & $2.5 \%$ & 717 & $-1,858$ & $-1,141$ & -382 & 912 & 530 \\
\hline $18.8 \%$ & $-4.7 \%$ & $-2.0 \%$ & $-6.4 \%$ & $9.5 \%$ & $3.0 \%$ & 874 & $-2,257$ & $-1,384$ & -466 & 1,113 & 647 \\
\hline $18.4 \%$ & $-4.6 \%$ & $-1.9 \%$ & $-6.3 \%$ & $9.2 \%$ & $2.9 \%$ & 852 & $-2,203$ & $-1,350$ & -455 & 1,086 & 631 \\
\hline
\end{tabular}

From the 1900 to the 1955 birth cohorts the age gap fell from 4.43 to 2.61 years. The analysis implies that nursing home expenditures by women fell by $\$ 1.35$ billion as a result of their spouses being 1.82 years younger. On the other hand, nursing home expenditures by men rose by $\$ 0.63$ billion a result of their spouses being 1.82 years older. Of course, more married women entered nursing homes as a result of this, primarily because the number of married women grew. However, this was more than offset by the reduction of nursing home utilization by unmarried women. On the other hand, fewer married men entered nursing homes, because there were fewer married men around, but this was more than offset by growth in the entrance of unmarried men.

Since our simplified model of nursing home entrance has some important limitations, we also performed sensitivity analysis to determine whether it greatly affected our results. We found that the limitations probably understate the impact of the changing age gap. The key output from the nursing home entrance model is the forecasted effect of marriage on the risk of nursing home entry. Increases in the estimated effect of marriage will raise our estimates of the age gap effect, since the effect of becoming widowed will be larger, and vice-versa. Comparing our estimated probabilities to actual rates of entrance reveals that the model probably understates (by ten percent on average) the risk of entrance for single people and overstates it for married people. Sensitivity analysis confirms that this limitation is likely to understate the effect of the changing age gap. Table 5 shows the effect on the estimated change in the nursing home population, from the 1900 to 1955 birth cohorts, of changing the risk of nursing home entrance by twenty percent. The first column shows the baseline estimates, normalized to unity. The next two demonstrate that across the board changes in nursing home risk have no impact on our estimates, because they affect unmarried 
and married people equally. The last two columns show that decreasing the nursing home risk of married people would raise our estimated effect of the age gap by about $25 \%$, while increasing this risk would lower it by about the same. Recall that our model overstated the risk for married people by about ten percent; the sensitivity analysis inflates their risk by twice that amount.

Table 5: $\quad$ Results of Sensitivity Analysis.

\begin{tabular}{lccccc}
\hline & $\begin{array}{c}\text { Base } \\
\text { Case }\end{array}$ & $\begin{array}{c}\text { Increased NH } \\
\text { Risk for All }\end{array}$ & $\begin{array}{c}\text { Decreased NH } \\
\text { Risk for All }\end{array}$ & $\begin{array}{c}\text { Increased NH } \\
\text { Risk for Married }\end{array}$ & $\begin{array}{c}\text { Decreased NH } \\
\text { Risk for Married }\end{array}$ \\
\hline Male Resident Change & 1.00 & 1.00 & 1.00 & 0.79 & 1.25 \\
Female Resident Change & 1.00 & 1.00 & 1.00 & 0.77 & 1.24 \\
Total Resident Change & 1.00 & 1.00 & 1.00 & 0.76 & 1.24 \\
\hline
\end{tabular}

Note:

Sensitivity analysis alters the forecasted Nursing Home risk for the stated population each population group by twenty percent, either upwards or downwards as indicated.

\section{Discussion}

Although on average husbands are still older than their wives, the average age gap has shrunk. As a result, women are less likely to enter nursing homes, while men are more likely to enter them. In terms of current dollars and health care technology, the 1955 birth cohort is likely to spend more than half a billion dollars less on nursing homes annually than the 1900 birth cohort simply because of the reduction in the age gap of spouses. Women in the younger cohort will spend $\$ 1.35$ billion less, while men will actually increase their spending by more than $\$ 0.60$ billion. As the age gap continues to decline (as depicted in Figure 1), nursing home expenditures may not rise as much as otherwise anticipated. While this factor should be included when making projections of nursing home demand, the effects are modest in relationship to the rise in nursing home demand resulting from the increasing number of people reaching old age.

The declining age gap between spouses is a consistent feature of this century, but little attention has been paid to it, particularly as it relates to health, mortality, and health care utilization. In this paper, we have focused exclusively on its impact upon nursing home utilization. While the effects on nursing home usage are indeed quite significant, this phenomenon may have effects that extend beyond this particular line of research. Changes in the age of spouses may impact overall health and thus influence the demand for health care. Alternatively, since widowhood is often a key cause of 
poverty among the elderly, these changes could also affect welfare receipt and other public programs.

\section{Acknowledgement}

This research was supported by the National Institute on Aging, R03 AG19900.

\section{Changes}

On July $28^{\text {th }} 2003$, per request of the author, the following change was made:

On page 279 , the sentence "We estimate that the decline in the difference in ages between spouses that took place between the birth cohorts of 1900 and 1955 may raise women's annual nursing home expenditures by about $\$ 1.4$ billion, but lower men's expenditures by about $\$ 600$ million."

was changed to:

"We estimate that the decline in the difference in ages between spouses that took place between the birth cohorts of 1900 and 1955 may lower women's annual nursing home expenditures by about $\$ 1.4$ billion, but raise men's expenditures by about $\$ 600$ million." 


\section{References}

Bergstrom, T. C. and M. Bagnoli (1993). "Courtship as a Waiting Game." Journal of Political Economy 101(1): 185-202.

Clark, S. C. (1995). "Advance Report on Final Marriage Statistics, 1989 and 1990." Monthly Vital Statistics Report 43(12).

Ebrahim, S., G. Wannamethee, et al. (1995). "Marital Status, Change in Marital Status, and Mortality in Middle-Aged British Men." American Journal of Epidemiology 142(8): 834-842.

Ettner, S. (1994). "The Effect of the Medicaid Home Care Benefit on Long-Term Care Choices of the Elderly." Economic Inquiry 32(1): 103-127.

Foley, D. J., A. M. Ostfeld, et al. (1992). "The Risk of Nursing Home Admissions in Three Communities." Journal of Aging and Health 4: 155-173.

Freedman, V. A., L. F. Berkman, et al. (1994). "Family Networks: Predictors of Nursing Home Entry." American Journal of Public Health 84: 843-845.

Garber, A. M. and T. MaCurdy (1990). Predicting Nursing Home Utilization Among the High-Risk Elderly. Issues in the Economics of Aging. D. A. Wise. Chicago, University of Chicago Press: 173-200.

Kemper, P. and C. Murtaugh (1991). "Lifetime Use of Nursing Home Care." New England Journal of Medicine 324: 595-600.

Lakdawalla, D. N. and T. J. Philipson (2002). "The Rise in Old-Age Longevity and the Market for Long-Term Care." American Economic Review 92(1): 295-306.

Lillard, L. A. and C. W. A. Panis (1996). "Marital Status and Mortality: The Role of Health." Demography 33(3): 313-327.

Norton, E. C. (1995). "Elderly Assets, Medicaid Policy, and Spend-Down in Nursing Homes." Review of Income and Wealth 41(3): 309-29.

OECD (1998). OECD Health Data 98: A Comparative Analysis of 29 Countries, OECD Electronic Publications.

Pezzin, L. E., P. Kemper, et al. (1996). "Does Publicly Provided Home Care Substitute for Family Care?" Journal of Human Resources 31(3): 650-676.

Spector, W. D., L. E. Pezzin, et al. (2000). The Characteristics of Long-Term Care Users. Washington, DC, AHRQ. 
Steinbach, U. (1992). "Social Networks, Institutionalization, and Mortality Among Elderly People in the United States." Journal of Gerontology: Social Sciences 47: S183-S190.

Stern, S. N. (1995). "Estimating Family Long-Term Care Decisions in the Presence of Endogenous Child Characteristics." Journal of Human Resources 30(3): 551-80.

United States Congress Ways and Means Committee (2000). Green Book. Washington, DC, Government Printing Office.

US Bureau of the Census (1998). Marital Status and Living Arrangements: Match 1998 (Update). Washington, DC, US Bureau of the Census.

US Department of Health and Human Services (1992). Life Tables for the United States Social Security Area, 1900-2080. Washington, DC, Social Security Administration. 